\title{
Esophageal Perforation and Imaging Findings in a Four Years Old Child
}

\author{
Halil Ibrahim Şara, (1) Turgay Kara, (1) Avni Merter Keçeli
}

Department of Radiology, University of Health Science, Konya Trainning and Research Hospital, Konya, Turkey

\section{ABSTRACT}

Esophageal perforation is a rare pathologic condition with high mortality. latrogenic, endoscopic interventions are the most common cause. Early diagnosis and treatment should be performed. The diagnosis of esophageal perforation is based on the clinical suspect and radiographic evidence. In this case study, a 4-year-old boy, who swallowed a coin and experienced endoscopic intervention leading iatrogenic esophageal perforation and pleural empyema, is presented usingimaging findings (direct chest X-ray, contrast-enhancedfluoroscopy, thorax computed tomography) and brief literature knowledge.

Keywords: Child, esophageal perforation, radiology

\section{INTRODUCTION}

Esophageal perforation is a life-threatening clinical condition with high morbidity and mortality. Clinical symptoms and findings are nonspecific. The variety of clinical findings delays diagnosis and makes it difficult. If clinical suspicion occurs, radiological imaging can be performed in the early stages for diagnosis. ${ }^{[1,2]}$

Please cite this article as: Şara Hi, Kara T, Keçeli AM. Esophageal Perforation and Imaging Findings in a Four Years Old Child. Anatol J Family Med 2020;3(1):76-80.

Address for correspondence: Dr. Turgay Kara. Department of Radiology, University of Health Science, Konya Trainning and Research Hospital, Konya, Turkey Phone: +90 5055197559 E-mail: trgykr@gmail.com

Received Date: 22.05 .2019 Accepted Date: 10.10 .2019 Published online: 01.04 .2020

(C) Copyright 2020 by Anatolian Journal of Family Medicine Available online at www.anatoljfm.org OPEN ACCESS

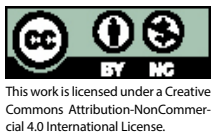

\section{CASE REPORT}

A 4-year-old boy was admitted to hospital with swallowing a coin. In his physical examination, wheezing was detected in both lungs. According to the age of the patient, the state of consciousness and cooperation were natural. The two-sided radiogram showed the density of metallic foreign bodies in the lower cervical region (Figure 1). It was observed that the coin was stuck at the level of physiological narrowing in cervical esophagus in the case that was evaluated by rigid esophagogoscope. Metallic foreign body could not be removed by esophagogoscope. In the meantime, the foreign body was displaced distally with the esophageal peristalsis. The patient was followed up to observe the movement of the foreign body in the gastrointestinal tract (GIS) and the rectal route under service conditions. The coin was spontaneously excluded by defecation after 24 hours. During this period, the patient developed cough, respiratory distress and fever. Chest radiogram revealed opacity in the right lung lower zone and right costophrenic angle was blunted. Thorax ultrasound revealed a pleural fluid with intense content and septa. Esophageal rupture and pleural empyema were suspected due to recent esophageal intervention history. In the upper GIS single-contrast fluoroscopic examination, it was seen that the oral opaque material was moving distal to the esophagus and the lumen was open. The first narrowing level of the esophagus revealed contour lobulation and filling area in the right lateral section. In the left 


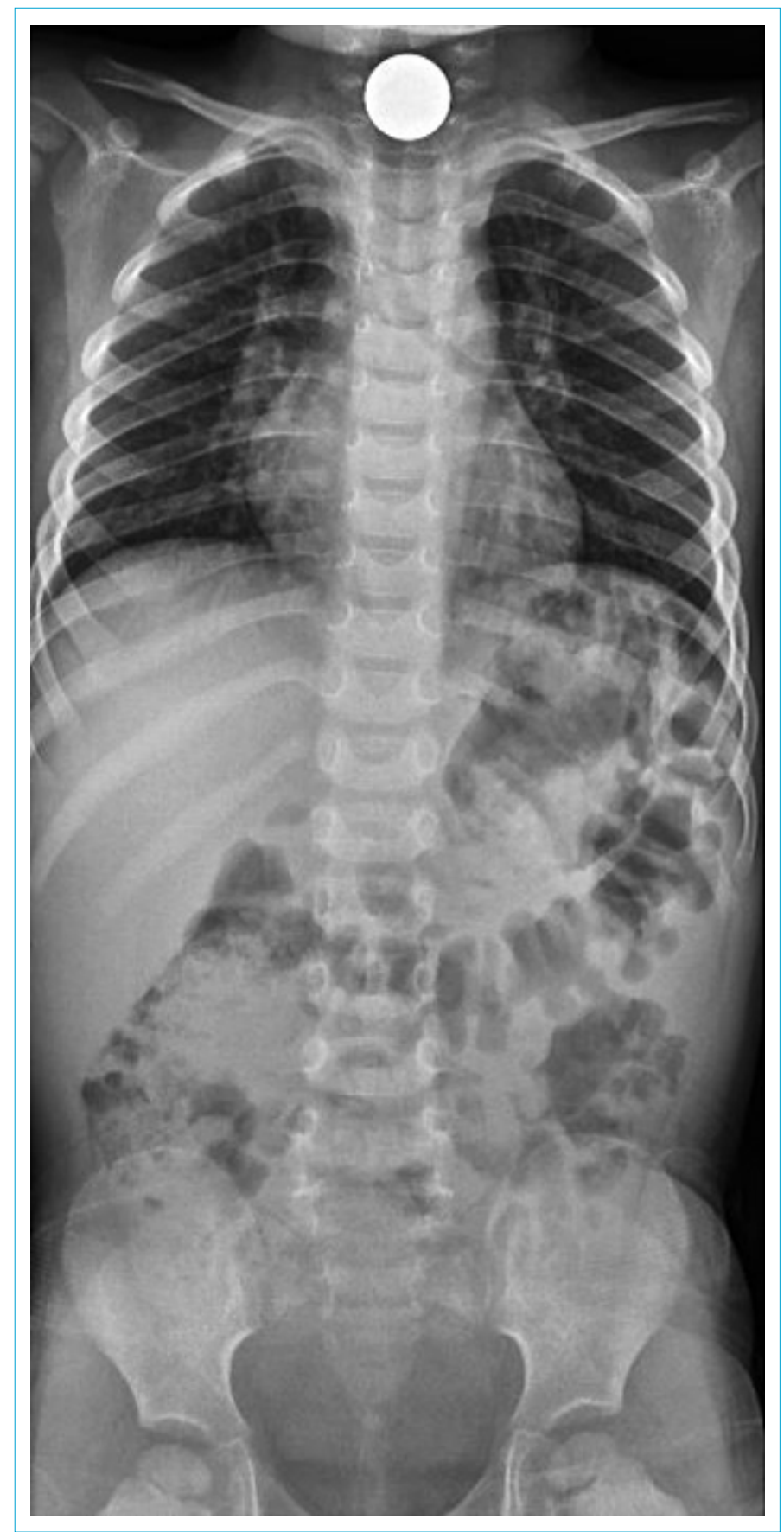

Figure 1. The two-sided radiogram showed the density of metallic foreign body in the lower cervical region.

lateral section of this area, opaque material was found to be extravasated at an area of $5 \mathrm{~mm}$ in size and progressed towards the pleural space (Figure 2). On follow-up, opaque substance leveling developed at the right costophrenic sinus level (Figure 3). He was diagnosed with esophageal perforation and pleural space fistulization. Because the clinical findings progressed to sepsis, the patient was admitted to the intensive care unit. In the follow-up, chest radiograms showed atelectasis areas in the pleural space

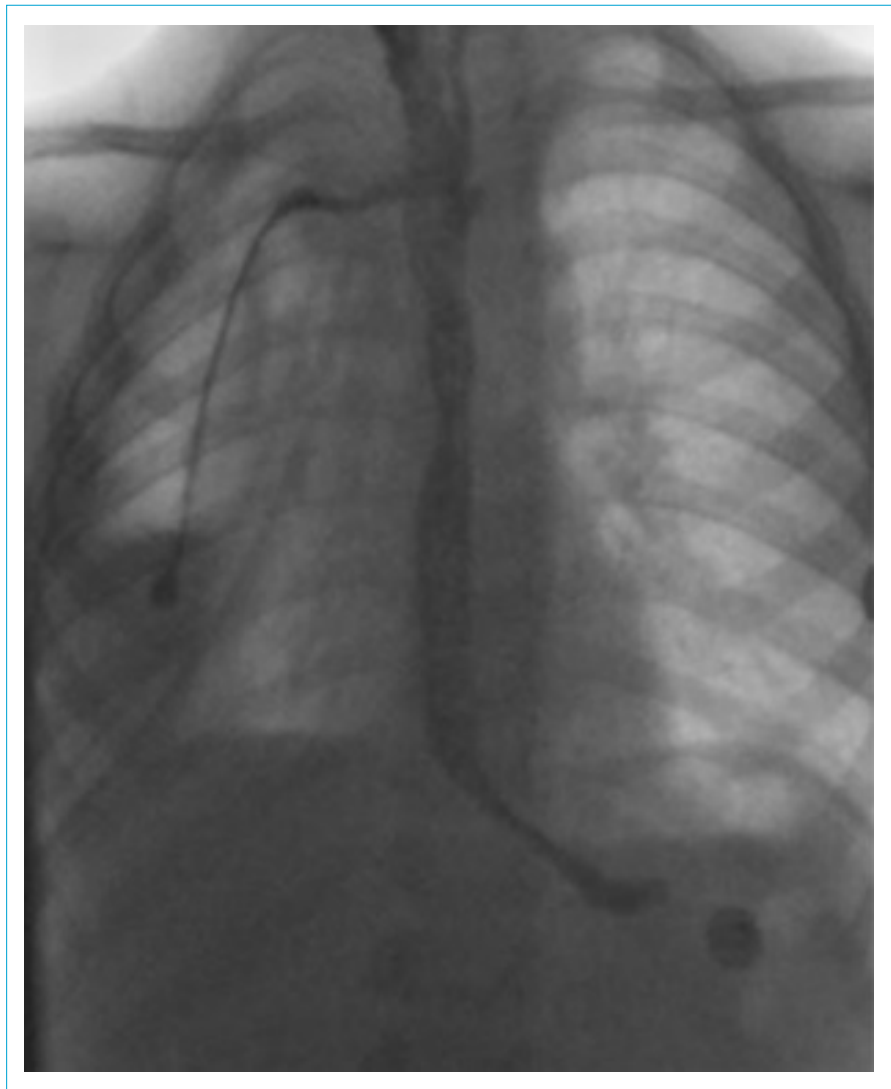

Figure 2. A Opaque material was found to be extravasated in fluoroscopic view.

of the right hemithorax and fluid areas in the lower-middle zone. The next day the leveled fluid in the right hemithorax was interpreted in favor of the upper-middle zone empyema (Figure 4). In the oral and intravenous contrastenhanced computed tomography (CT) examinations, it was observed that the oral opaque material accumulated in the pleural space (Figure 5).

Catheter application was performed for the primary suturing of the esophageal rupture area and drainage of the pleural fluid. In pleural fluid samples, it was found that the fluid was transudative and there was no growth in microbiological evaluation. The patient whose ruptured esophageal area was repaired was discharged with health after two months treatment in thoracic surgery clinic. On the last chest radiography, there was no radiopathology other than pleural thickening due to fibrotic parenchymal changes in the right lung lower zone (Figure 6).

\section{DISCUSSION}

Esophageal perforation is a rare, life-threatening condition. ${ }^{[1,2]}$ Various factors, such as difficulty in access to the esophagus, lack of strong serosal layer and proximity to vital structures, cause this to be associated with high mor- 


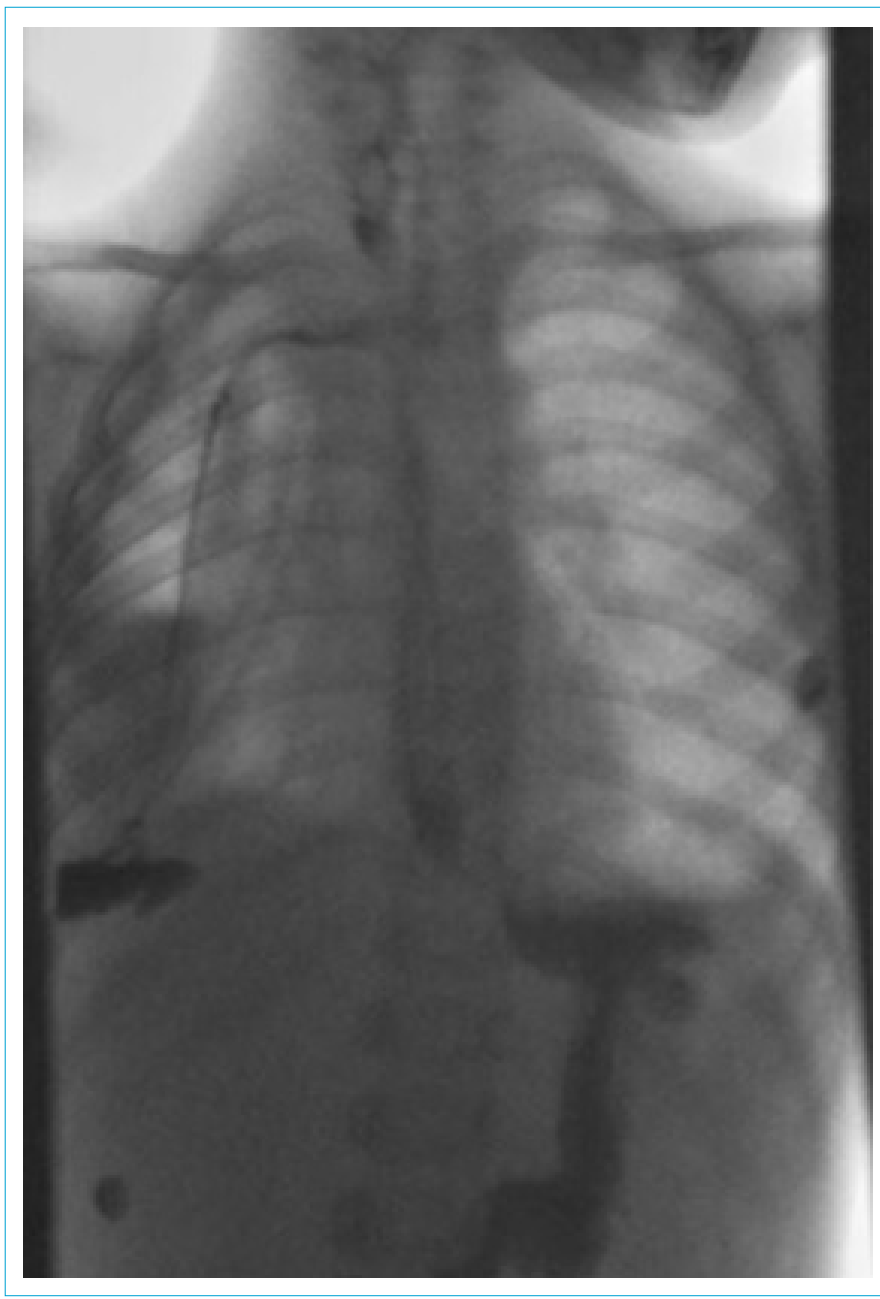

Figure 3. Opaque substance leveling developed at the right costophrenic sinus in follow up fluoroscopy.

bidity and a mortality rate of at least $20 \% \cdot{ }^{[3-5]}$ In addition, the lack of individual experience related to this particular condition, as well as the variety of clinical symptoms, can be shown as other conditions that make it difficult to diagnose rapidly. ${ }^{[6]}$

The incidence of spontaneous esophageal perforation is not clearly known, but in a population-based study in Iceland, the incidence was reported as 3.1/1000.000/ year. ${ }^{[4]}$ Most patients are in the $6^{\text {th }}$ decade, and esophageal perforation is more common in males. ${ }^{[5,7]}$

We should note that $50 \%$ of the esophageal perforations are iatrogenic and are usually associated with endoscopic intervention in the upper GIS, while one third is spontaneous perforations. ${ }^{[4,8,9]}$ It has also been reported that it may be seen as a complication of surgical procedures for the tissues surrounding the esophagus. ${ }^{[10-12]}$ The incidence of iatrogenic perforation is less than $0.5 \%$ when all procedures for the esophagus are considered. ${ }^{[13]}$ In children, esopha-

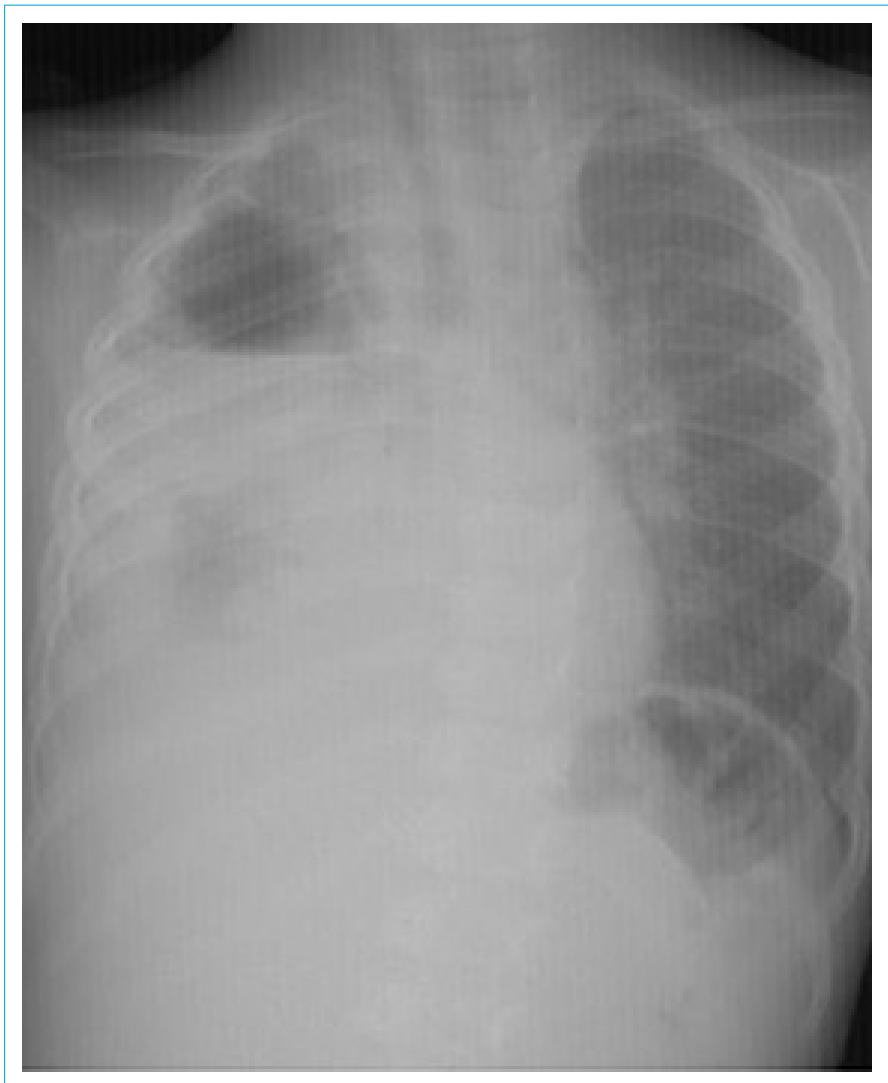

Figure 4. Chest $X$ ray shows upper-middle zone empyema.
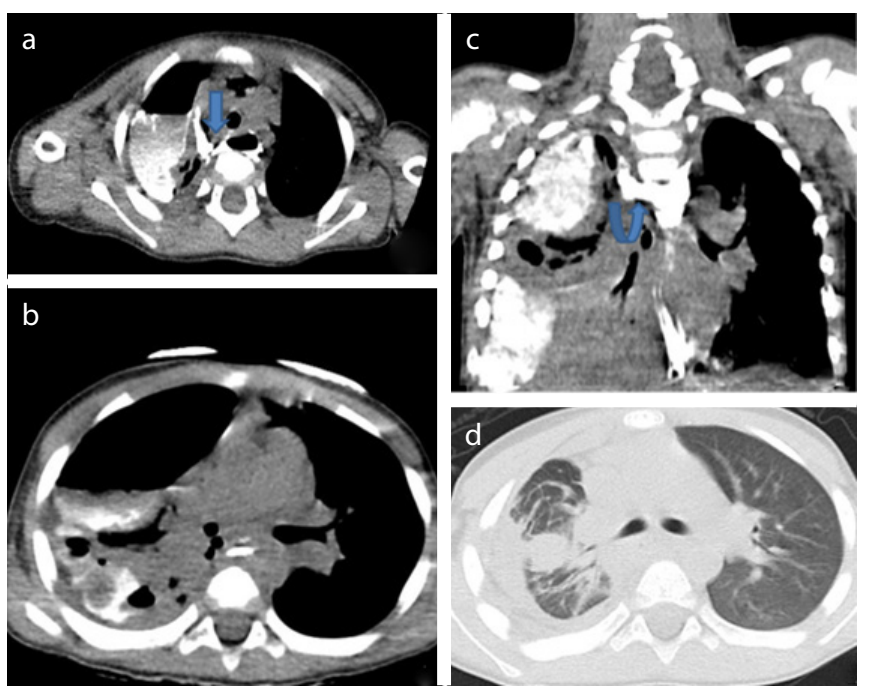

Figure 5. Oral and intravenous contrast enhanced computed tomography reveals oral opaque material accumulated in the pleural space.

geal injuries usually arise from accidental swallowing of

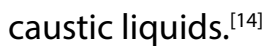

Although symptoms and symptoms vary, chest pain is the major symptom of esophageal perforation. The pain is sudden onset and spreads to the back and left shoulders. In 


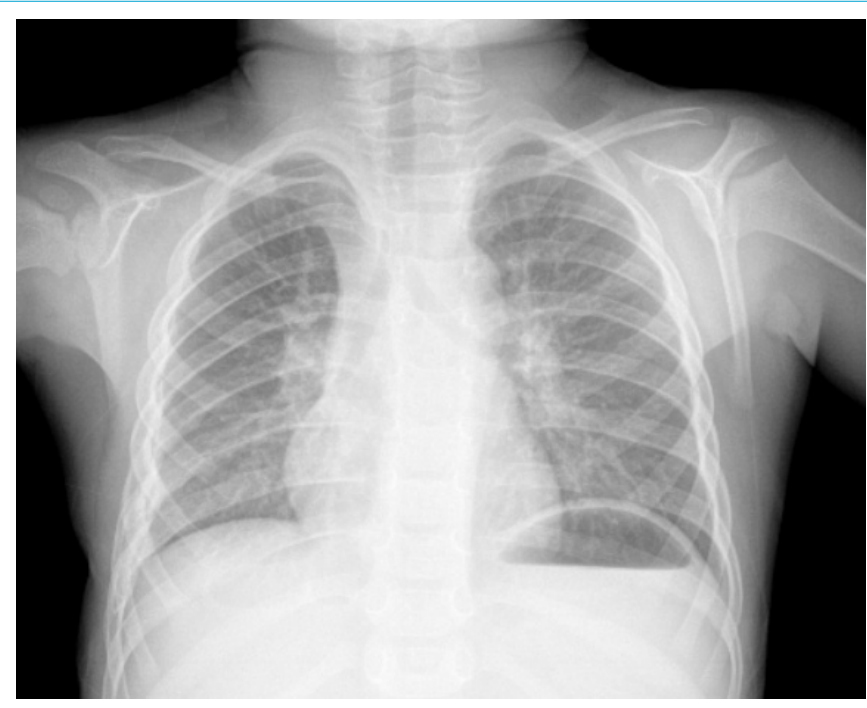

Figure 6. Control chest $\mathrm{X}$ ray is normal except pleural thickenning.

approximately $25 \%$ of the patients, this pain is followed by vomiting and shortness of breath. Vomiting, chest pain, and subcutaneous emphysema are known as the Mackler triad. ${ }^{[5,15]}$ Acute abdominal or epigastric pain may be present in patients with a perforation at the level of the gastroesophageal junction. Symptoms of the gastrointestinal tract, such as hematemesis and melena may be seen, albeit rarely. ${ }^{[5]}$ Physical examinations may include fever and tachycardia. Systemic inflammatory response develops with perforation. Bacterial mediastinitis may result in fatal statements, such as cardiopulmonary collapse and multiorgan failure. Therefore, early diagnosis and treatment of patients with suspected esophageal perforation arevery important to avoid such fatal consequences.

The diagnosis of esophageal perforation is based on radiographic evidence. Radiological imaging findings mayinclude indirect findings, such as pleural effusion, pneumomediastinum, subcutaneous emphysema, hydrothorax, pneumothorax and collapse of the lung. ${ }^{[16-18]}$ If there is a suspicion of perforation, a water-soluble oral contrast agent is used instead of barium in fluoroscopy. Chest radiograms obtained by oral administration of water-soluble iodinated contrast agents may show extravasation of contrast media.

CT of the thorax and upper abdomen obtained by oral contrast media may demonstrate esophageal wall integrity and contrast extravasation. CT can help determine the extent of perforation and the degree of involvement of the wall in patients with trauma or caustic injury. Although the indications for endoscopy are controversial, endoscopy can be considered in cases where the radiographic examination with suspected perforation is negative or when the contrast agents cannot be swallowed for technical reasons. Non-surgical treatment may be the appropriate treatment for many patients with iatrogenic perforation. ${ }^{[2]}$ Surgical drainage methods should be considered in cases, such as gross contamination. Primary repair is usually possible in early applications. T-tube applicated repair is an alternative treatment method that enables controlled esophageal fistula formation without contamination. ${ }^{[19]}$ It should be kept in mind that esophageal resection may be the most appropriate treatment in some patients according to the patient's clinical condition and the cause of perforation. ${ }^{[1]}$ In addition, endoscopic esophageal stents and endoscopic vacuum sponge (sponge) are other methods used in the treatment and in accelerating healing. ${ }^{[20-23]}$

\section{CONCLUSION}

Early diagnosis and treatment of esophageal perforation may be difficult due to non-specific symptoms. Therefore, in case of clinically suspicious cases, repeated physical examination and imaging should be performed if necessary. With this case report, we hope to increase awareness among physicians about this rare condition and contribute to medical literature along with imaging findings.

\section{Disclosures}

Informed Consent: Written informed consent was obtained from the parents of the patient for the publication of the case report and the accompanying images.

Conflict of Interest: Authors declare that there are no financial or other relations that could lead to a conflicts of interest.

Peer-review: Externally peer-reviewed.

Financial Disclosure: There is no financial disclosure.

Authorship contributions: Concept - A.M.K.; Design - H.I.S.; Supervision - T.K.; Materials - A.M.K.; Data collection \&/or processing - H.I.S.; Analysis and/or interpretation - T.K.; Literature search - H.i.S.; Writing - H.I.S.; Critical Review - T.K.

\section{REFERENCES}

1. Sepesi B, Raymond DP, Peters JH. Esophageal perforation: surgical, endoscopic and medical management strategies. Curr Opin Gastroenterol 2010;26:379-83. [CrossRef]

2. Abbas G, Schuchert MJ, Pettiford BL, Pennathur A, Landreneau J, Landreneau J, et al Contemporaneous management of esophageal perforation. Surgery 2009;146:749-55. [CrossRef]

3. Ryom P, Ravn JB, Penninga L, Schmidt S, Iversen MG, Skov-OIsen $\mathrm{P}$, et al. Aetiology, treatment and mortality after oesophageal perforation in Denmark. Dan Med Bull 2011;58:A4267.

4. Vidarsdottir $\mathrm{H}$, Blondal $\mathrm{S}$, Alfredsson $\mathrm{H}$, Geirsson A, Gudbjartsson $\mathrm{T}$. Oesophageal perforations in Iceland: a whole population study on incidence, aetiology and surgical outcome. Tho- 
rac Cardiovasc Surg 2010;58:476-80. [CrossRef]

5. Søreide JA, Viste A. Esophageal perforation: diagnostic workup and clinical decision-making in the first 24 hours. Scand J Trauma Resusc Emerg Med 2011;19:66. [CrossRef]

6. Onat S, Ulku R, Cigdem KM, Avci A, Ozcelik C. Factors affecting the outcome of surgically treated non-iatrogenic traumatic cervical esophageal perforation: 28 years experience at a single center. J Cardiothorac Surg 2010;5:46. [CrossRef]

7. Bhatia P, Fortin D, Inculet RI, Malthaner RA. Current concepts in the management of esophageal perforations: a twenty-seven year Canadian experience. Ann Thorac Surg 2011;92:209-15.

8. Vallböhmer D, Hölscher AH, Hölscher M, Bludau M, Gutschow C, Stippel D, et al. Options in the management of esophageal perforation: analysis over a 12-year period. Dis Esophagus 2010;23:185-90. [CrossRef]

9. Gander JW, Berdon WE, Cowles RA. Iatrogenic esophageal perforation in children. Pediatr Surg Int 2009;25:395-401.

10. Kau RL, Kim N, Hinni ML, Patel NP. Repair of esophageal perforation due to anterior cervical spine instrumentation. Laryngoscope 2010;120:739-42. [CrossRef]

11. Sreedharan L, Lakshmanan P, Shenfine J, Gibson MJ, Griffin SM. Thoracic vertebral osteomyelitis secondary to chronic esophageal perforation. Spine J 2009;9:e1-5. [CrossRef]

12. Akbulut G, Gunay S, Aren A, Bilge O. A rare complication after thyroidectomy: esophageal perforation. Ulus Travma Derg 2002;8:250-2. [CrossRef]

13. Ivatury RR, Moore FA, Biffl W, Leppeniemi A, Ansaloni L, Catena F, et al. Oesophageal injuries: Position paper, WSES, 2013.
World J Emerg Surg 2014;9:9. [CrossRef]

14. Riffat F, Cheng A. Pediatric caustic ingestion: 50 consecutive cases and a review of the literature. Dis Esophagus 2009;22:89-94. [CrossRef]

15. Mackler SA. Spontaneous rupture of the esophagus; an experimental and clinical study. Surg Gynecol Obstet 1952;95:34556.

16. Exarhos DN, Malagari K, Tsatalou EG, Benakis SV, Peppas C, Kotanidou $A$, et al. Acute mediastinitis: spectrum of computed tomography findings. Eur Radiol 2005;15:1569-74. [CrossRef]

17. Huber-Lang M, Henne-Bruns D, Schmitz B, Wuerl P. Esophageal perforation: principles of diagnosis and surgical management. Surg Today 2006;36(4):332-40. [CrossRef]

18. Young CA, Menias CO, Bhalla S, Prasad SR. CT features of esophageal emergencies. Radiographics 2008;28:1541-53.

19. Qadir I, Zafar H, Khan MZ, Sharif HM. T-tube management of late esophageal perforation. J Pak Med Assoc 2011;61:418-20.

20. Salminen P, Gullichsen R, Laine $S$. Use of self-expandable metal stents for the treatment of esophageal perforations and anastomotic leaks. Surg Endosc 2009;23:1526-30. [CrossRef]

21. Loske G, Schorsch T, Müller C. Endoscopic vacuum sponge therapy for esophageal defects. Surg Endosc 2010;24:2531-5.

22. Wolfson D, Barkin JS. Treatment of Boerhaave's Syndrome. Curr Treat Options Gastroenterol 2007;1071-7.

23. Strauss DC, Tandon R, Mason RC. Distal thoracic oesophageal perforation secondary to blunt trauma: case report. World J Emerg Surg 2007;2:8. [CrossRef] 